\title{
MODELING, ANALYSIS AND ANFIS CONTROL FOR DTC-SVM OF INDUCTION MOTOR OF AN ELECTRIC VEHICLE USING ELECTRICAL DIFFERENTIAL
}

\author{
Laxmi Narasimha Rao Yalavarthi \\ Assistant Professor,M.V.S.R Enginering College, Hyderabad, India \\ Dr. Ravindranath Gurram \\ Professor ,HOD EEE, Matrusri Engineering College, Hyderabad, India
}

\begin{abstract}
This paper presents modeling, analysis and simulation of DTC-SVM of Induction motor which suits for application of electric vehicle $(E V)$ with two independent rear wheel drive. DTC-SVM endure from torque ripples and poor response time to sudden changes in load. To over the above onerous of DTC-SVM to electric vehicle (EV) a new technique called ANFIS is proposed to Electric Vehicle(EV) with two three-phase induction motors horsed on rear wheels. The speed of wheels is calculated independently during the turning with the Electrical Differential system computations which distributes torque and power to each wheel motor according to the prerequisite, comply the speed of each motor to the driving conditions. The Proposed control system uses the vehicle speed, which is different from wheel speed characterized by a slip in the driving mode, as an input. The analysis and simulations lead to the conclusion that the proposed system is feasible. Simulation results on a test vehicle propelled by two induction motors showed that the proposed control approach operates satisfactorily.
\end{abstract}

Keywords: Space vector Pulse width Modulation (SVPWM), ANFIS \& DTCSVPWM.

Cite this Article: Laxmi Narasimha Rao Yalavarthi and Dr. Ravindranath Gurram, Modeling, Analysis and ANFIS Control for DTC-SVM of Induction Motor of an Electric Vehicle using Electrical Differential, International Journal of Electrical Engineering \& Technology, 10(2), 2019, pp. 57-68.

http://iaeme.com/Home/issue/IJEET?Volume=10\&Issue=2

\section{INTRODUCTION}

The principal inhibition in vehicle design for transit is the development of a high safety and comfortable vehicle. Taking into account this inhibition, our interest has been focused on the Electrical Vehicle, with independent driving wheel-motor drive shaft. This disposition is a 
convincing solution, the pollution of this vehicle is strongly decreased and electric traction gives the possibility to achieve accurate and quick control of the distribution torque. Torque control can be assured by the inverter and this vehicle does not crave for a mechanical differential gear or gearbox. One of the main concerns in the depiction of this vehicle is to assume the car endurance. During normal driving condition, all drive wheel system requires a commensurate dissemination of torque in the both sides. In recent years, due to problems like the energy catastrophe and environmental profanation, the Electric Vehicle (EV) has been researched and developed more and more broadly.

This paper proposes a Adaptive Neuro Fuzzy Interference system(ANFIS)tra ction control approach of an electrical differential system for an EV propelled by two induction motor drives (one for each rear wheel). Adaptive Neuro Fuzzy Interfernce system(ANFIS) conceits have become an active research area in power electronics and motor drives. Because of the necessity for robust intelligence in a network erudition process, applying Adaptive Neuro Fuzzy Interference system (ANFIS) to system identification and control dynamics has been compromising alternative to process control. Adaptive Neuro Intelligence system(ANFIS)s can be applied to control and identify nonlinear systems since they approximate any desired degree of accuracy with a wide range of nonlinear models. The rotor speed information of an induction motor in the DTC-SVPWM using ANFIS method is obtained using ANFIS technique.

In fact, the feed forward network is used along with fuzzy rules. The feed forward multilayer and fuzzy rule structure makes it sturdy under parameter variations and system noises. Moreover, the proposed Feed forward neural network with fuzzy -based speed estimator, which replaces the speed sensor in the control approach scheme, takes into account vehicle aerodynamics and is not applied to sole induction motors. It should be noted that the induction motor was appropriate because it seems to be the candidate that bestfulfils the major engrosment for EV propulsion

\section{VEHICLE MODEL}

\subsection{Nomenclature}

$v \quad$ Vehicle speed.

a Vehicle acceleration.

$m$ Vehicle mass.

$\alpha$ Grade angle.

$F_{t e}$ Tractive force.

$F_{r r}$ Rolling resistance force.

$F_{h c}$ Hill climbing force.

$F_{l a}$ Linear acceleration force.

$F_{w a}$ Angular acceleration force.

Tm Motor torque.

$P_{t e} \quad$ Vehicle driving power.

$J$ Total inertia (rotor and load).

$G$ Gear ratio.

$\eta_{g}$ Gear system efficiency.

$r$ Tire radius. 
Modeling, Analysis and ANFIS Control for DTC-SVM of Induction Motor of an Electric Vehicle using Electrical Differential

\subsection{Dynamics Analysis}

The prospective control approach takes into recital vehicle aerodynamics and is not applied to sole induction motors. This model is based on the principles of vehicle mechanics and aerodynamics The total tractive effort is then given by

$$
F_{t e}=F_{r r}+F_{a d}+F_{h c}+F_{l a}+F_{w a} \text {. }
$$

This is the force mobilizing the vehicle ahead and disseminate to the ground through the wheels (Fig. 1). $F_{l a}$ and $F_{w a}$ have been added in this paper for a more accurate representation of the needed force to accelerate the vehicle. Undeniably, we should consider rotational acceleration as well as linear acceleration of electric vehicle as such stability is to be considered because of its higher angular speeds. It should be noted that $\mathrm{F}_{l a}$ and $\mathrm{F}_{w a}$ will be negative if the vehicle is slowing down and that $\mathrm{F}_{h c}$ will be negative if it is going downhill. Accordingly the motor torque required for an angular acceleration will be given by

$$
T_{m}=J G \eta_{g} r a \text {. }
$$

Certainly, the power required to commute vehicle at a speed $v$ has to indemnify for counteracting forces

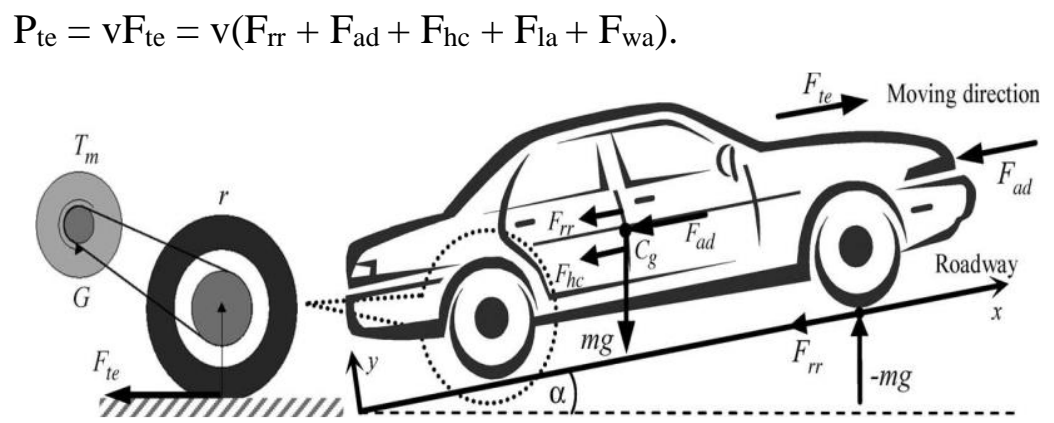

Figure 1 Forces acting on electric Vehicle.

\section{PRINCIPLES OF DTC-SVM WITH IMAGINARY REFERENCE PHASE VOLTAGES}

DTC- SVPWM scheme for two-level inverters, each reference phase voltage is compared with the triangular carrier and the individual pole voltages are generated, independent of each other. To achieve the maximum expedient peak amplitude of the fundamental phase voltage, in linear modulation, a common mode voltage, $\mathrm{V}_{\text {offsetl }}$, is added to the reference phase voltages, where the magnitude of voffset 1 is given by

$$
\mathrm{V}_{\text {offset } 1}=-\left(\mathrm{V}_{\max }+\mathrm{V}_{\text {min }}\right) / 2
$$

In Equation (4), $V_{\max }$ is the maximum magnitude of the three sampled reference phase voltages, while $V_{\min }$ is the minimum magnitude of the three sampled reference phase voltages in a sampling interval. Equation(4) is based on the fact that in a sampling interval, the reference phase which has lowest magnitude crosses the triangular carrier first, and causes the first transition in the inverter switch in state, although the reference phase, which has the superlative magnitude, crosses the carrier last and causes the last switching transition in the inverter switching states. Thus the switching periods of the simmering vectors can be dogged from the (max-phase and min-phase) specimen allusion phase voltage amplitudes in a twolevel inverter scheme. 


\section{Algorithm}

Step1: Sample Van,Vbn, and Vcn from the torque and flux errors through

Step2: $\quad$ Tas $=$ Van*Ts/Vdc;

$\mathrm{Tbs}=\mathrm{Vbn} * \mathrm{Ts} / \mathrm{Vdc}$;

$\mathrm{Tcs}=\mathrm{Vcn} * \mathrm{Ts} / \mathrm{Vdc}$;

Step3: $\quad$ Toffset1 $=-(\max ($ Tas,Tbs,Tcs $)+\min ($ Tas, Tbs,Tcs $)) / 2$;

Step4:

$$
\begin{aligned}
& \text { Tas } *=\text { Tas }+ \text { Toffset } 1 \\
& \text { Tbs } * \text { Tbs }+ \text { Toffset } 1 \\
& \text { Tcs } *=\text { Tcs }+ \text { Toffset } 1
\end{aligned}
$$

Once the calculation of

$$
\begin{aligned}
& \text { Tas* }=\text { Tas+ Toffset } 1 ; \\
& \text { Tbs* }=\text { Tbs }+ \text { Toffset } 1 \text { and }
\end{aligned}
$$

Tcs* $=$ Tcs+ Toffset 1 is done then Triangular wave is compared with the reference signal to obtain the switching states of each inverter.

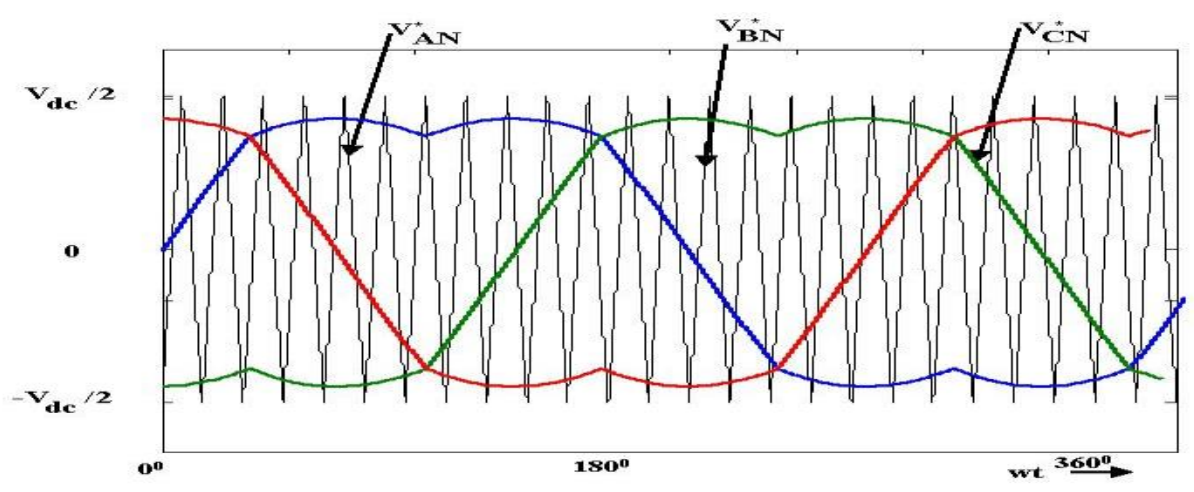

Figure 2 Comparison of reference phase voltages with triangular wave

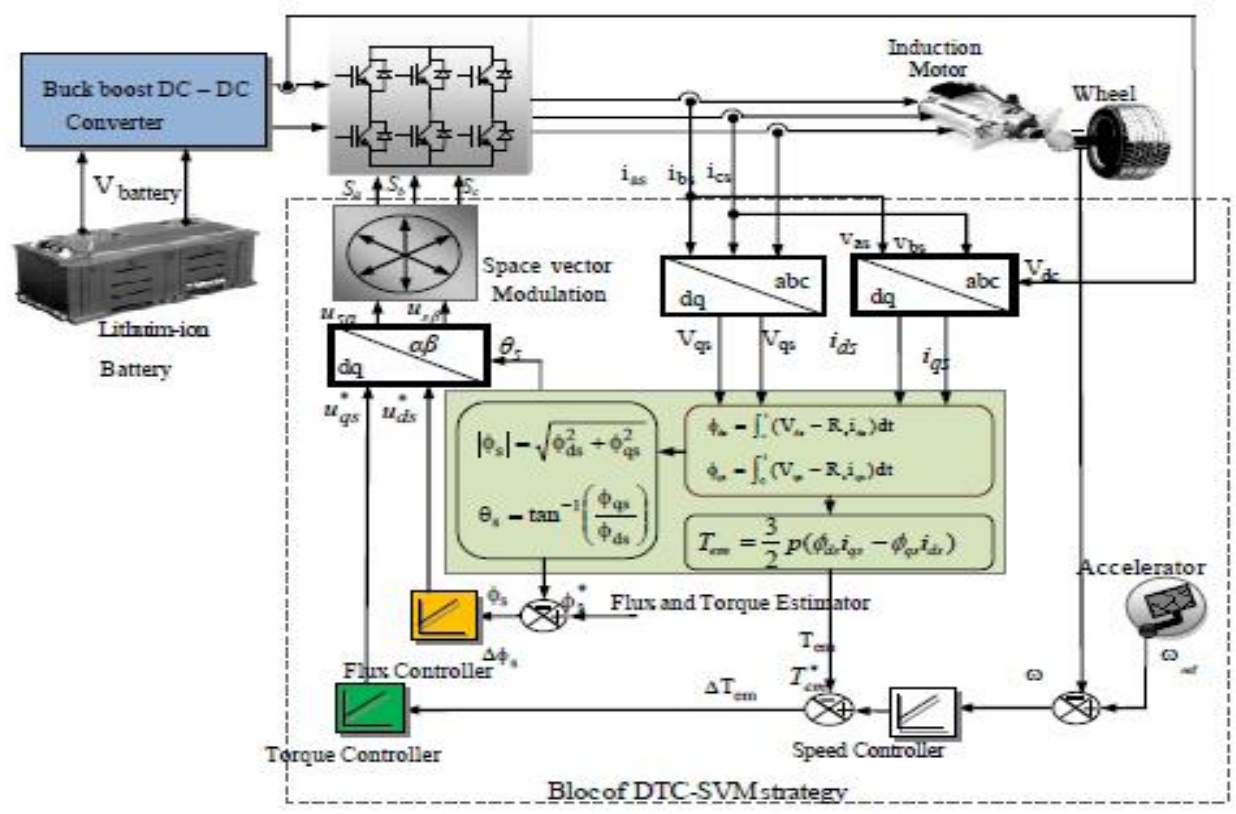

Figure 3 DTC SVM of 3 phase Induction Motor 
Modeling, Analysis and ANFIS Control for DTC-SVM of Induction Motor of an Electric Vehicle using Electrical Differential

\section{PROPOSED DTC SVM WITH ANFIS CONTROLLER TO ELECTRIC VEHICLE}

\subsection{Adaptive Neuro Fuzzy Inference System}

The ANFIS is able of learning the preferred mapping involving the inputs and outputs signals of the system. Since the ANFIS do not use the arithmetical representation of the system, the same. The ANFIS are excellent estimators in non linear systems. Various ANFIS based control approach have been implemented for DTC-SVM of induction motor drive to conquer the system drawback. In this paper ,NN flux point estimation, segment range and switching vector range design is projected. A neuro fuzzy structure is a fuzzy structure that practices a derived learning algorithm or stimulated by the theory of neural networks to determine its factors (fuzzy set and fuzzy rules) by handling data models. NFC is the arrangement of Fuzzy Inference System (FIS) and NN. The fuzzy logic is activated permitting to the fuzzy rule where inputs are obtained from Neural network trained. The neural network formation data set is utilised by fuzzy rules. The NFC function is clarified in the following section.

\subsection{Fuzzy Logic Controller}

A mathematical system that analyzes along input values in terms of logical variables that take on continuous values between Zeros and ones Fuzzy logic gives the linguistic approaches control adaptation from practiced familiarity in automatic control schemes. In the fuzzy control scheme, the operation of controller is mainly constructed on fuzzy rules, which are created using fuzzy set theory. Fuzzy controller plays an important role in the compensation of PQ problem .the steps involved in fuzzy controller are fuzzification, decision making, and fuzzification is the method of changing the crisp value into fuzzy value.

\subsection{Proposed FLC structure}

Fuzzification strategy

- Data base building

- Rule base elaboration

- Interface machine elaboration

- Defuzzification strategy.

Also, outline of FLC can give keen both small signal and large signal dynamic execution at same time, which is likely with linear control method. The advancement of fuzzy logic approach here is constrained to the plan and structure of the controller. The contributions of FLC are characterized change of error. Fuzzy sets are characterized for each information and output variable. There are five fuzzy levels which described in Rule table. The enrollment capacities for input and output factors are triangular. The min-max technique interface engine is used. The fuzzy technique utilized as a part of this FLC is focal point of territory. The entire arrangement of control rules is appeared in Table.1. Each of the 25 control rules speaks to the coveted controller reaction to a specific circumstance. 
Table 1 Fuzzy logic Controller

\begin{tabular}{|c|c|c|c|c|c|c|c|c|}
\hline & & $\begin{array}{l}\mathbf{N} \\
\mathbf{L}\end{array}$ & $\begin{array}{l}\mathbf{N} \\
\mathbf{M}\end{array}$ & $\begin{array}{l}\mathbf{N} \\
\mathbf{S}\end{array}$ & $\begin{array}{l}\mathbf{Z} \\
\mathbf{E}\end{array}$ & $\begin{array}{l}\mathbf{P} \\
\mathbf{S}\end{array}$ & $\begin{array}{l}\mathbf{P} \\
\mathbf{M}\end{array}$ & $\begin{array}{l}\mathbf{P} \\
\mathbf{B}\end{array}$ \\
\hline \multirow{3}{*}{$\begin{array}{l}\mathbf{k} \\
\mathbf{p}\end{array}$} & $\mathrm{N}$ & I & $M$ & $\mathrm{~S}$ & $M$ & $\mathrm{~S}$ & $M$ & $I$ \\
\hline & $Z$ & L & $\mathbf{M}$ & L & $Z$ & L & $\mathbf{M}$ & L \\
\hline & $P$ & L & $\mathbf{M}$ & L & $z$ & L & $\mathrm{M}$ & L \\
\hline \multirow[t]{3}{*}{$\mathbf{k}_{\mathbf{i}}$} & $\mathbf{N}$ & $Z$ & $\mathrm{~S}$ & $\mathbf{M}$ & L & $\mathbf{M}$ & $\mathrm{S}$ & $Z$ \\
\hline & $Z$ & $Z$ & $\mathrm{~S}$ & $\mathbf{M}$ & L & $\mathbf{M}$ & $\mathrm{S}$ & $Z$ \\
\hline & $P$ & $Z$ & $\mathbf{M}$ & $\mathrm{L}$ & L & L & $\mathrm{M}$ & $Z$ \\
\hline
\end{tabular}

\subsection{Designing \& Training of ANN}

An Artificial neural Network (ANN), regularly called a "neural Network" (NN), is a systematic model or Computational model in view of natural neural systems. It comprises of an interrelated collecting of artificial neurons and procedures data utilizing a connectionist way to deal with calculation. By and large an ANN is a versatile framework that progressions its structure in light of outside or interior data that moves through the system along with the learning stage. In more functional terms neural systems are non-direct measurable information demonstrating apparatuses. They can be utilized to display complex connections amongst information sources and yields or to discover designs in information. $\mathrm{NN}$ is a manmade brainpower method that is utilized for producing preparing informational collection and testing the connected information. A sustain feed forward sort $\mathrm{NN}$ is utilized The structure of the NN is described as follows.

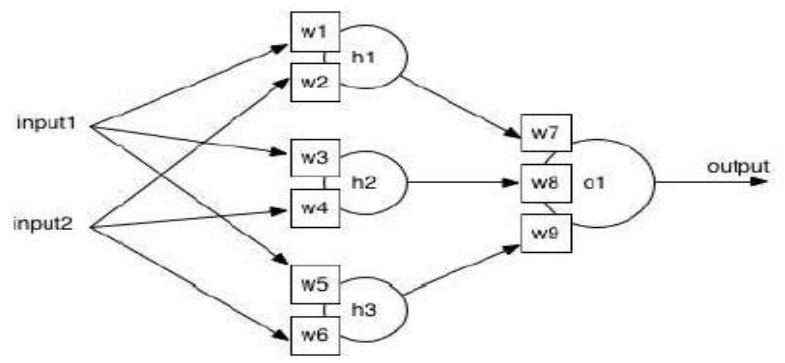

Figure 4 Artificial Neural Network

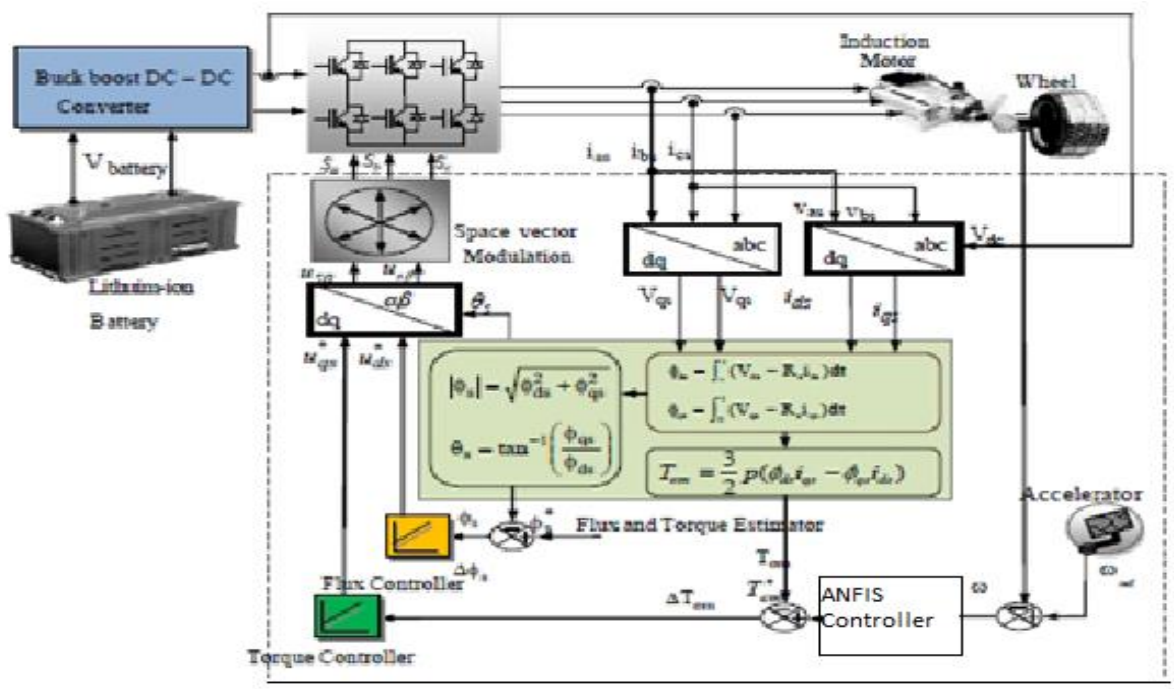

Figure 5.DTC SVPWM with ANFIS for Electric Vehicle 
Modeling, Analysis and ANFIS Control for DTC-SVM of Induction Motor of an Electric Vehicle using Electrical Differential

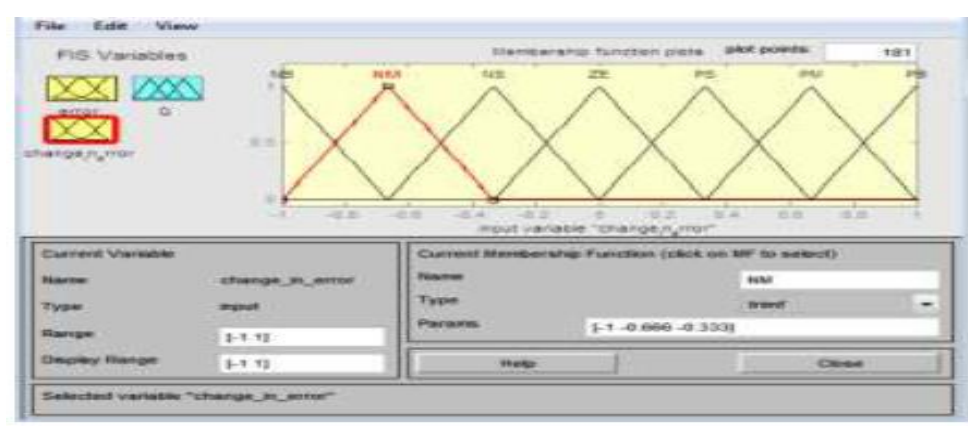

Figure 6 Membership function for input $\mathrm{Kp}$ and $\mathrm{Ki}$

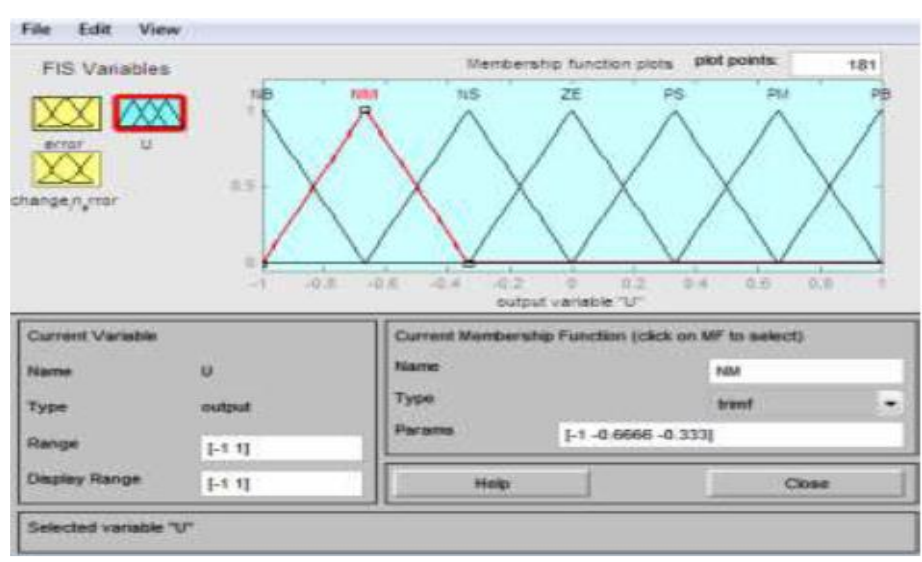

Figure 7 Membership functions for outputs of Kp and Ki

\section{ELECTRIC DIFFERENTIAL AND ITS IMPLEMENTATION}

Fig. 8 illustrates the implemented system (electric and mechanical components) in the MatlabSimulink environment. It should be noted that the inverters share the same dc bus whose voltage is supposed to be stable.. The proposed control system principle could be summarized as follows: a) A speed network control is used to control each motor torque; b) The speed of each rear wheel is controlled using speed difference feedback. Since the two rear wheels are directly driven by two separate motors, the speed of the outer wheel will need to be higher than the speed of the inner wheel during steering maneuvers (and vice-versa). This condition can be easily met if the speed estimator is used to obtain sense the angular speed of the steering wheel using ANFIS mtethod. The common reference speed $\omega$ ref is then obtained by the accelerator pedal command. The original reference speed for the left drive $\omega$ ref-left and the right drive $\omega$ ref-right are then obtained by adjusting the common reference speed $\omega$ ref using the output signal from the RNN speed estimator. If the vehicle is turning right, the left wheel speed is enhanced and the right wheel speed remains equal to the common reference speed $\omega$ ref .

From this model, the following characteristic can be

calculated:

$$
R=L \tan \delta
$$

where $\delta$ is the steering angle. Therefore, the linear speed of each wheel drive is given by

$$
\begin{gathered}
\bar{V} 1=\omega \mathrm{V}(R-d / 2) \\
V 2=\omega \mathrm{V}(R+d / 2)
\end{gathered}
$$

and their angular speed by 


$$
\begin{aligned}
& \omega \text { est } 1=\frac{L-\left(\frac{d}{2}\right) \tan \partial}{L} \omega \mathrm{V} \\
& \omega \text { est } 1=\frac{L+\left(\frac{d}{2}\right) \tan \partial}{L} \omega \mathrm{V}
\end{aligned}
$$

where $\omega \mathrm{V}$ is the vehicle angular speed according to the center of turn.

The difference between wheel drive angular speeds is then

$$
\Delta \omega=\omega \text { est } 1-\omega \text { est } 2=\frac{-d \tan \delta}{L} \omega \mathrm{V}
$$

and the steering angle indicates the trajectory direction

$-\delta>0 \Rightarrow$ Turn left

$\delta=0 \Rightarrow$ Straight ahead

$\delta<0 \Rightarrow$ Turn right.

In accordance with the above described equation, Fig. 8 shows the electric differential system block diagram as used for simulations, where $K 1=1 / 2$ and $K 2=-1 / 2$.

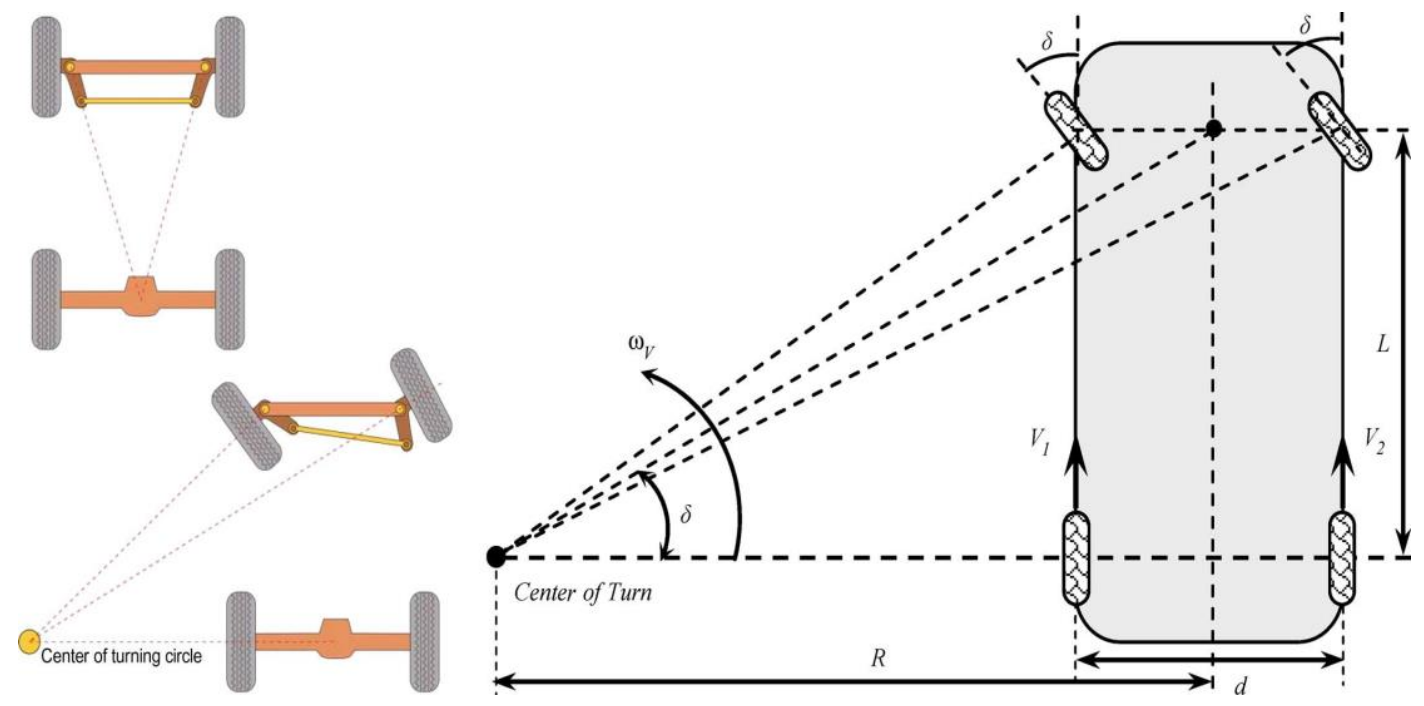

Figure 8 Driving Trajectory Model

\section{SIMULATION RESULTS/CONCLUSIONS}

The IMD in both the modes has been developed incorporating PI and ANFIS which results in simulation model of scalar DTC-SVPWM based speed control of Electric Vehicle. By adjusting the weights ANN controller is designed where as the training obtained through learning algorithms of ANN resulted in ANFIS. Hence a performance of PI based IMD is investigated at various operating conditions. A comparison of the responses obtained of the conventional PI, FLC and ANN based IMD have proved the superiority of the ANFIS 
Modeling, Analysis and ANFIS Control for DTC-SVM of Induction Motor of an Electric Vehicle using Electrical Differential

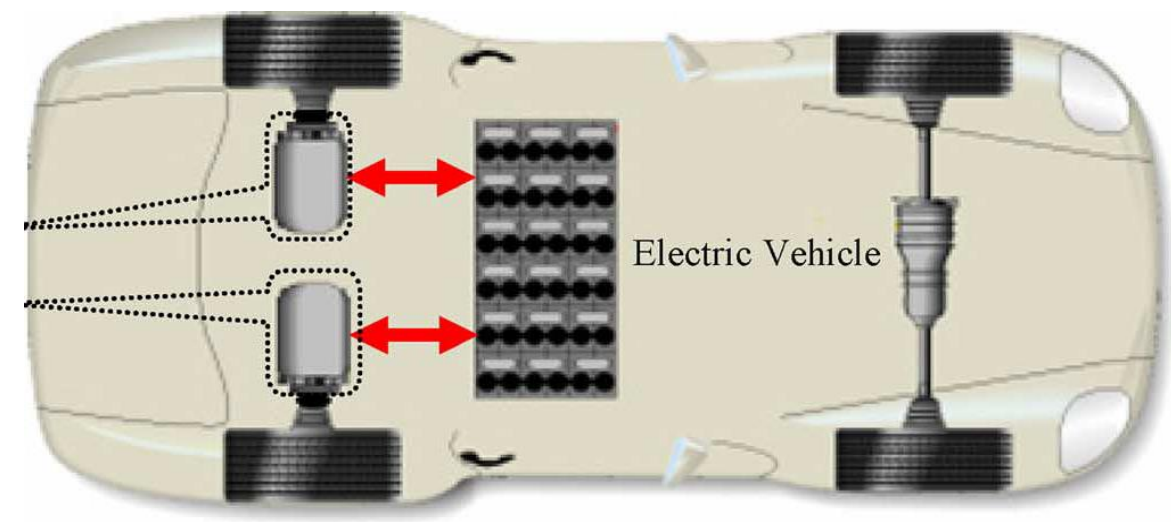

Figure 9 Motors Coupled to rear wheels

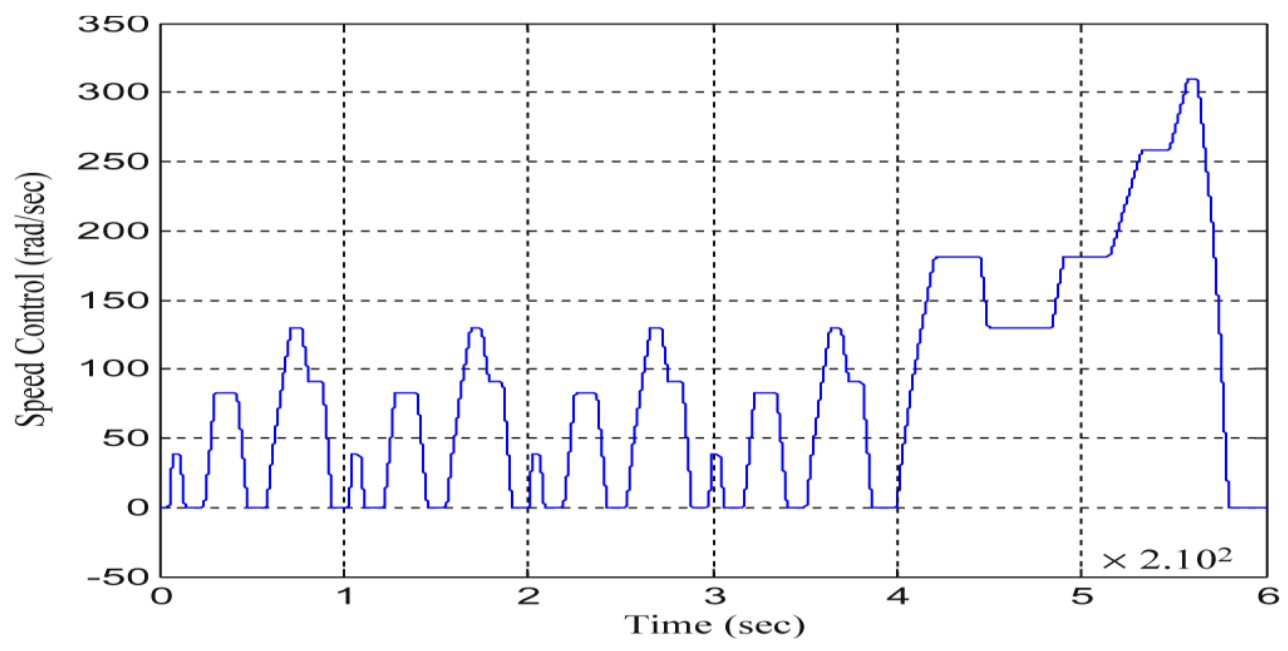

Figure 10 Speed variations of Induction motor

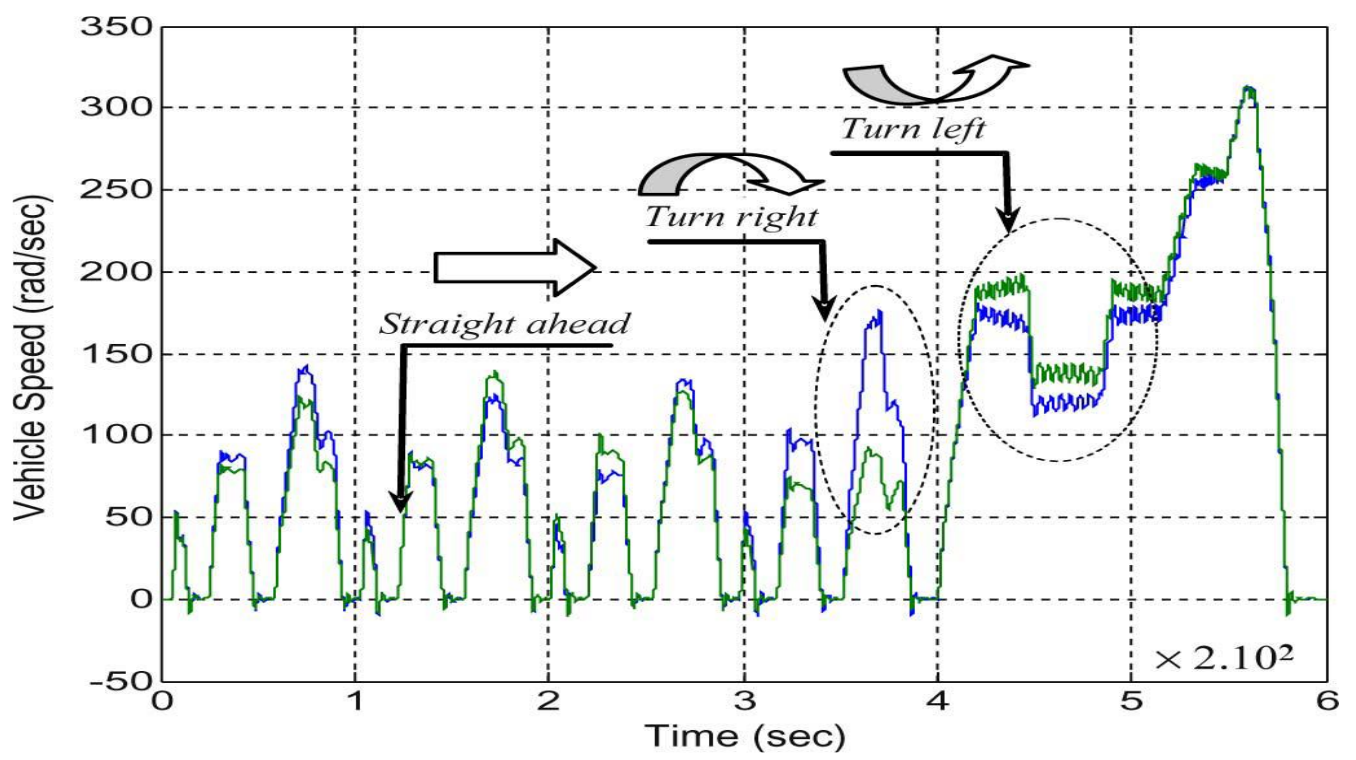

Figure 11 Vehicle speed for different situations 


\section{At No Load Conditions}

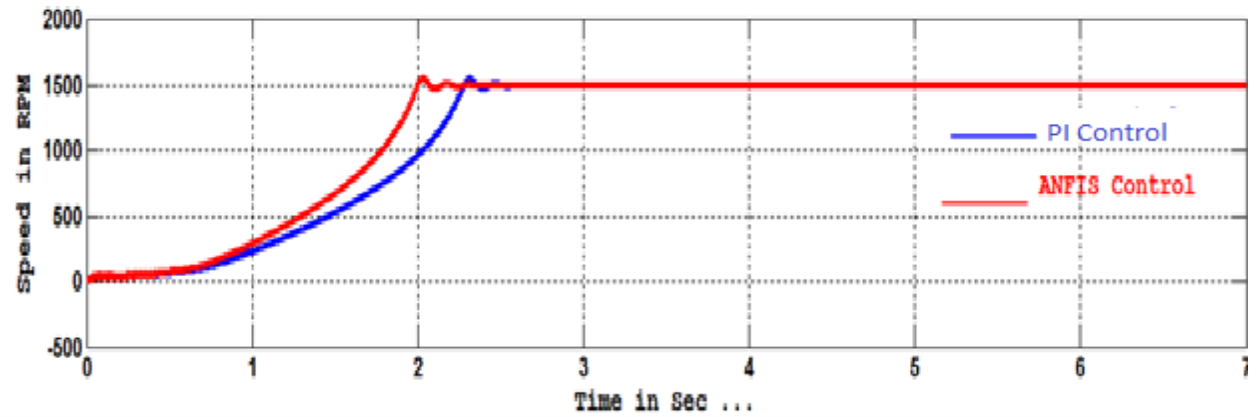

Figure 12 Comparison of speeds using PI and ANFIS Controller

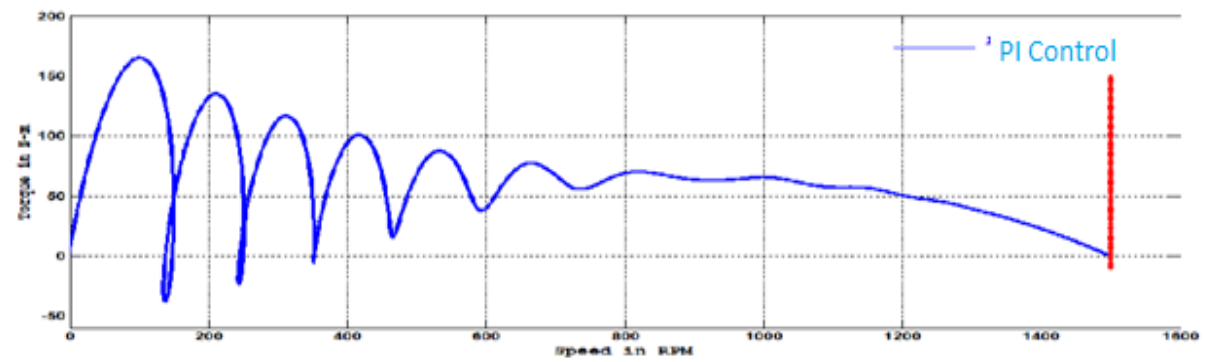

Figure 13.Speed torque characteristics of Induction motor using PI Control

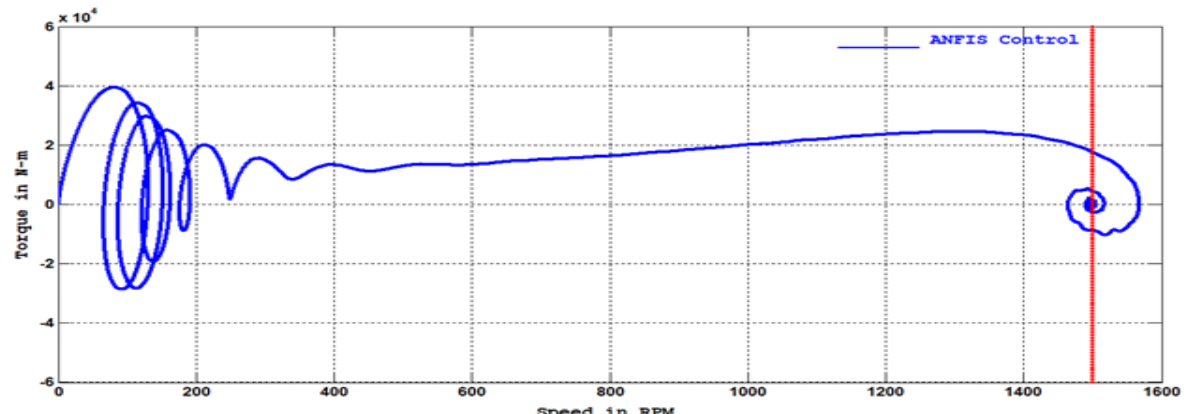

Figure 14 Speed torque characteristics of Induction motor using ANFIS Control

It is observed from Fig. initial torque variations in IM drive using ANFIS controller is much lower compared to the IM drive using PI controller.

\section{At load Conditions}

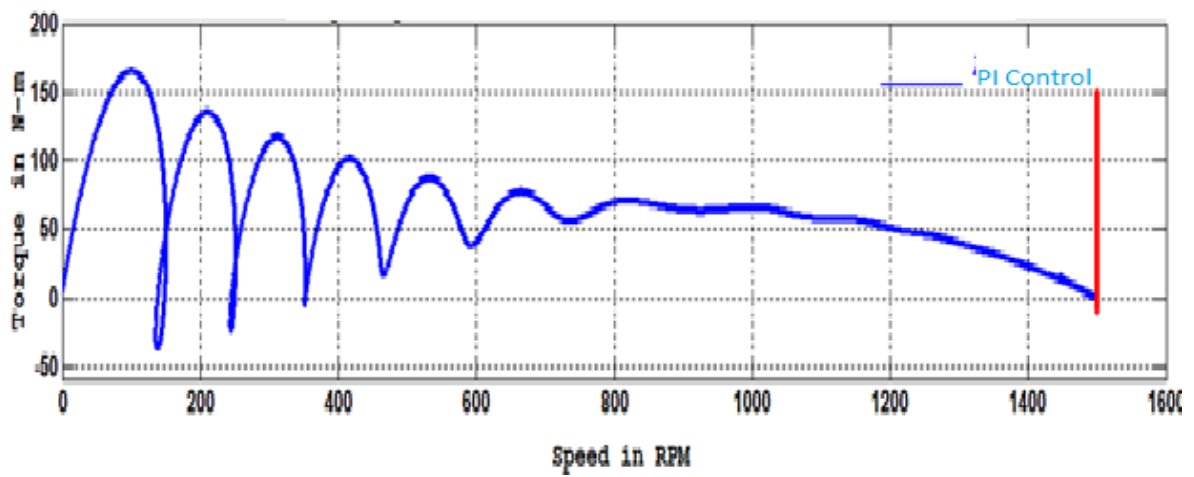


Modeling, Analysis and ANFIS Control for DTC-SVM of Induction Motor of an Electric Vehicle using Electrical Differential

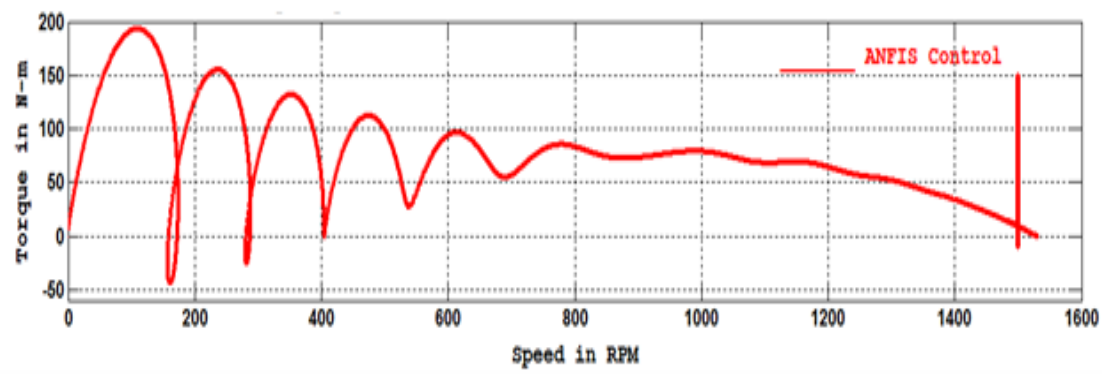

Figure 15 Speed torque characteristics of Induction motor using PI and ANFIS Control

The torque ripple is small for ANFIS in comparison to PI as shown in Fig10. From speed characteristics, ANFIS controller tracks the speed command rapidly, smoothly and with relatively small steady state error when compared to PI controller.
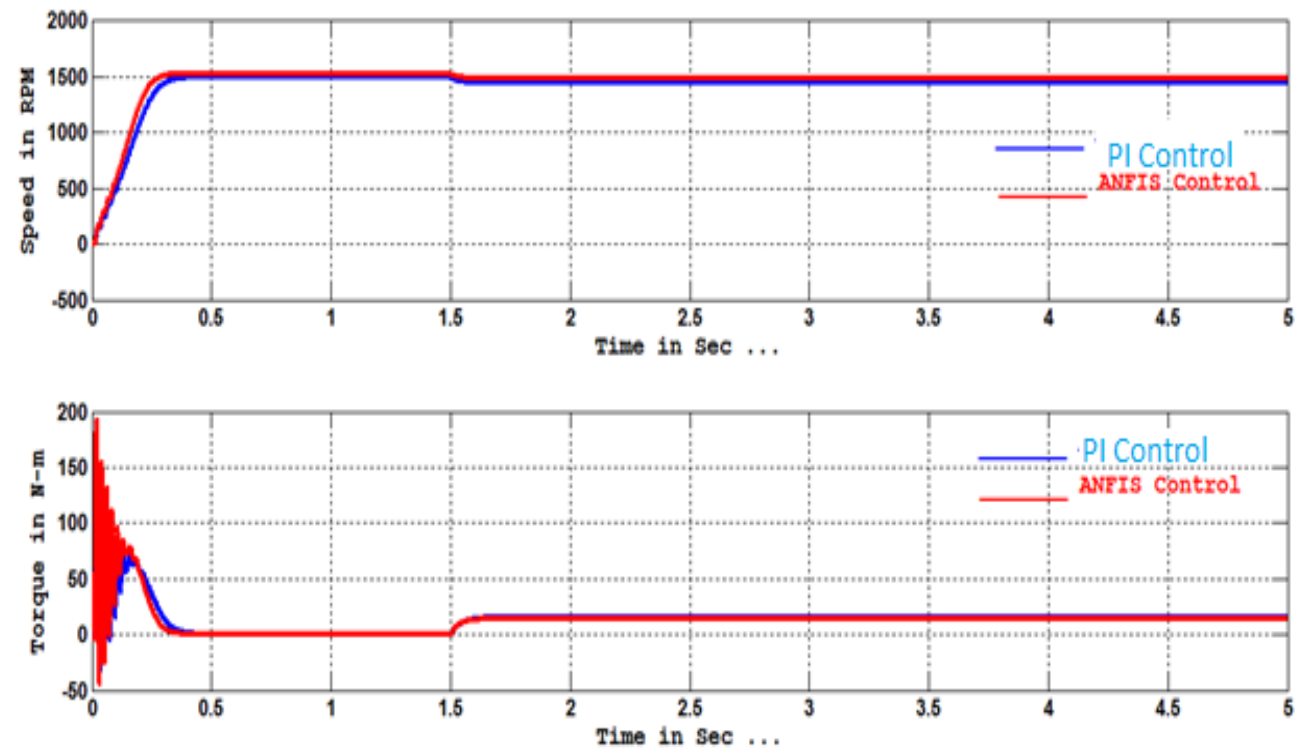

Figure 16. Speed Torque characteristics of PI and ANFIS Controller

Table2. Comparison of PI and ANFIS control of Induction motor subjected to electric vehicle

\begin{tabular}{|l|c|c|c|c|c|}
\hline \multirow{2}{*}{ Controller } & \multicolumn{2}{|c|}{ Response time of speed } & \multicolumn{2}{c|}{ Torque response } & $\begin{array}{c}\text { Torque } \\
\text { Ripples }\end{array}$ \\
\cline { 2 - 6 } & Overshoot & $\begin{array}{c}\text { Settling time } \\
\text { (sec) }\end{array}$ & Overshoot & $\begin{array}{c}\text { Settling time } \\
(\mathbf{s e c})\end{array}$ & $(\%)$ \\
\hline PI(No-load) & 0.7 & 1.9 & 55 & 1.9 & 7.32 \\
\hline ANFIS(No-Load) & 0.65 & 2.3 & 35 & 2.3 & 2.35 \\
\hline PI(Load) & 0.495 & 0.38 & 35 & 0.38 & 6.5 \\
\hline ANFIS(Load) & 0.45 & 0.29 & 15 & 0.29 & 1.95 \\
\hline
\end{tabular}

The results obtained prove that the solutions with AI controllers are much better than the one with PI controller. Simulation results demonstrate that ANFIS controller is better than the classical PI controller in performance. Both ANN and fuzzy controllers prove that the actual speed could track the command one rapidly, smoothly and with relatively small steady state error for the advanced control of squirrel cage induction motor. Both controllers work very well at different operating points. ANFIS controller greatly improves the transient response with faster dynamic response. For instantaneous load change ANFIS controller attains faster 
steady state. For gradual change in load, if the load is changed suddenly the steady state value is reached faster by ANFIS controller. This proves the strength of ANFIS controller.

\section{REFERENCES}

[1] J.K. Moharana, Analysis, Simulation and Comparison of Conventional and SVPWM on STATCOM Operation with Linear loads in Power System: International Journal of Electrical Engineering \& Technology, 9(2), 2018, pp. 110-114.

[2] T. Subhashini, P. Maheswari, G. Sharmila and T.B. Gopinath, SVPWM Using SiC, GaN Power Driven Motors for Sea Water Cooling System \& Ballast Water Management. International Journal of Mechanical Engineering and Technology, 8(4 ), 2017, pp. 01-12

[3] Anitha Sampathkumar, Three Stage Induction Engine Drive System Utilizing Converter SVPWM Inverter Fed from Photovoltaic Panel, International Journal of Mechanical Engineering and Technology 8(8), 2017, pp. 1523-1530.

[4] Rajasekharachari k, K.Shalini, Kumar .k, S.R.Divya, Advanced Five Level - Five Phase Cascaded Multilevel Inverter With Svpwm Algorithm International Journal Of Electrical Engineering \& Technology (IJEET), Volume 4, Issue 4, July-August (2013), pp. 144-158 